\title{
Inflammatory and clinical predictors of permanent atrial fibrillation
}

\author{
Ivana Jurin ${ }^{1 *}$ \\ Tomislav Letilović², \\ Irzal Hadžibegović', \\ Diana Rudan', \\ Vanja Ivanović \\ Mihajlović', \\ Sandra Jakšić \\ Jurinjak', \\ Jasmina Ćatić', \\ Petra Vitlov', \\ Mario Sičaja', \\ Boris Starčević'
}

'University Hospital Dubrava, Zagreb, Croatia

2University Hospital Merkur, Zagreb, Croatia

RECEIVED:

September 9, 2017

ACCEPTED:

September 26, 2017

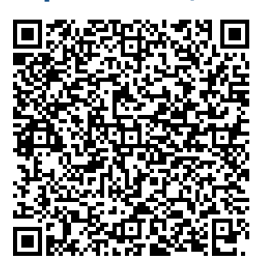

KEYWORDS: atrial fibrillation, $\mathrm{CHA}_{2} \mathrm{DS}_{2}$-VASc score, HATCH score, LADS score, inflammation. CITATION: Cardiol Croat. 2017;12(9-10):374. | https://doi.org/10.15836/ccar2017.374

*ADDRESS FOR CORRESPONDENCE: Ivana Jurin, Klinička bolnica Dubrava, Avenija Gojka Šuška 6, HR-10000 Zagreb, Croatia. / Phone: +385-98-559-387 / E-mail: ivana.sakic@yahoo.com

ORCID: Ivana Jurin http://orcid.org/0000-0002-2637-9691 • Tomislav Letilović http://orcid.org/0000-0003-1229-7983 Irzal Hadžibegović http://orcid.org/0000-0002-3768-9134 • Diana Rudan http://orcid.org/0000-0001-9473-2517 Vanja Ivanović Mihajlović http://orcid.org/0000-0001-6931-5404 • Sandra Jakšić Jurinjak http://orcid.org/0000-0002-7349-6137 Jasmina Ćatić http://orcid.org/0000-0001-6582-4201 • Petra Vitlov http://orcid.org/0000-0001-6983-1409 Mario Sičaja http://orcid.org/0000-0003-0773-4720 • Boris Starčević http://orcid.org/0000-0002-3090-2772

IIIIIIIIIIIIIIIIIIIIIIIIIIIIIIIIIIIIIIIIIIIIIIIIIIIIIIIIIIIIIIIIIIIIIIIIIIIIIIIIIIIIIIIIIIIIIIIIIIIIIIIIIIIIIIIIIIIIIIII

Aim: Principal aim of our prospective study was to evaluate aforementioned correlation of atrial fibrillation (AF) progression with inflammation. We tried to seek for inflammatory markers, that are readily available and could be related to AF progression ${ }^{1}$. We compared the predictive power of those markers to the clinical tools specifically designed for AF progression prediction such as the HATCH score [hypertension, age > 75 years, previous transient ischemic attack (TIA) or stroke (doubled), chronic obstructive pulmonary disease, heart failure (doubled)]. Predictive power of those inflammatory markers was further compared to predictive power of $\mathrm{CHA}_{2} \mathrm{DS}_{2}$-VASc score, used for prediction of $\mathrm{AF}$ adverse events. Finally, it was compared to LADS score [left atrial diameter ( $0-2$ points), age (0-2 points), diagnosis of stroke ( $0-1$ point), and smoking status currently ( $0-1$ point)] that was designed to identify acute stroke and transitory ischemic attack (TIA) patients with a greater chance of having AF. ${ }^{2}$

Patients and Methods: The study included 579 consecutive patients of which 302 had paroxysmal atrial fibrillation, 107 had persistent atrial fibrillation and 170 had permanent atrial fibrillation. The study included patients who were hospitalized in our department between June 2012 and May of 2016. In the follow up period we enrolled only patients with paroxysmal and persistent atrial fibrillation. After a follow up period of 12-36 months of all 409 patients, 107 patients developed permanent atrial fibrillation.

Results: Red cell distribution width ( $p=0.036)$, MPV to platelet count ratio $(p=0.011)$, lymphocytes $(p=$ $0.004)$ and neutrophils to lymphocyte ratio $(p=0.023)$ were found to be significant predictors of atrial fibrillation progression. In univariate analysis, age, platelets, mean platelet volume to platelet count ratio (MPV/platelet count), red cell distribution width (RDW) lymphocytes, neutrophils to lymphocyte ratio (N/L), $\mathrm{CHA}_{2} \mathrm{DS}_{2}$ VASC score, EF, LA size, HATCH and LADS score, and hypertension were significantly associated with AF progression. In multivariate analysis, only $\mathrm{CHA}_{2} \mathrm{DS}_{2}$-VASc score $(\mathrm{P}=0.024)$ and ejection fraction $(\mathrm{P}=0.003)$ were shown to be independent risk factors for AF progression.

Conclusion: These clinical and inflammatory markers could help us to determine which patients are at higher risk to develop permanent atrial fibrillation and therefore prevention of this progression remains an important target in the management of AF.
LITERATURE IIIIIIIIIIIIIIIIIIIIIIIIIIIIIIIIIIIIIIIIIIIIIIIIIIIIIIIIIIIIIIIIIIIIIIIIIIIIIIIIIIIIIIIIIIIIIIIIIIII

1. Shukla A, Curtis AB. Avoiding permanent atrial fibrillation: treatment approaches to prevent disease progression. Vasc Health Risk Manag. 2014:10:1-12. https://doi.org/10.2147/VHRM.S49334

2. de Vos CB, Pisters R, Nieuwlaat R, Prins MH, Tieleman RG, Coelen RJ, et al. Progression from paroxysmal to persistent atrial fibrillation clinical correlates and prognosis. J Am Coll Cardiol. 2010 Feb 23;55(8):725-31. https://doi.org/10.1016/j.jacc.2009.11.040 